\title{
COVID-19 and Cardiovascular Comorbidities
}

\author{
Authors \\ Dirk Müller-Wieland', Nikolaus Marx¹, Michael Dreher², Katharina Fritzen³ ${ }^{3}$ Oliver Schnell ${ }^{3,4}$
}

Affiliations

1 Clinic for Cardiology, Angiology and Internal Care Medicine (Medical Clinic I) Universitatsklinikum Aachen, Aachen

2 Clinic for Pneumology and Internal Intensive Care Medicine (Medical Clinic V, Uniklinik RWTH Aachen, Aachen

3 Sciarc GmbH, Baierbrunn

4 Forschergruppe Diabetes e.V., Munich Neuherberg

\section{Key words}

SARS-CoV-2, COVID-19, obesity, diabetes mellitus, hypertension, cardiovascular incidences, cardiovascular disease

$\begin{array}{lc}\text { received } & 07.09 .2020 \\ \text { revised } & 21.09 .2020 \\ \text { accepted } & 23.09 .2020 \\ \text { published online } & 06.11 .2020\end{array}$

\section{Bibliography}

Exp Clin Endocrinol Diabetes 2022; 130: 178-189

DOI 10.1055/a-1269-1405

ISSN $0947-7349$

(C) 2020. Thieme. All rights reserved.

Georg Thieme Verlag KG, Rüdigerstraße 14,

70469 Stuttgart, Germany

\section{Correspondence}

Dirk Müller-Wieland

Clinic for Cardiology, Angiology and Internal Intensive Care

Medicine (Med. Clinic I), University Hospitall Aachen, AöR

Pauwelsstraße 30

52074 Aachen

Deutschland

dirmueller@ukaachen.de

\section{ABSTRACT}

The emergence of a new coronavirus - severe acute respiratory syndrome coronavirus 2 (SARS-CoV-2) - has resulted in a global pandemic. The associated coronavirus disease 2019 (COVID-19) has resulted in a high number of death worldwide. Observational studies and case reports have provided insights that older age and the presence of chronic diseases is frequently associated with a higher COVID-19 severity. These individuals also seem to have a higher risk of mortality due to COVID-19. In this review we provide insights into the impact chronic diseases associated with the cardiovascular system, such as obesity, diabetes mellitus, hypertension and cardiovascular disease might have on SARS-CoV-2 infection and COVID-19. Additionally we review recommendations and guidance's of international scientific associations and discuss which key learnings might be of importance for the future.

$\begin{array}{ll}\text { ABBREVIATIONS } \\ \text { ARDS } & \text { Acute respiratory distress syndrome } \\ \text { SARS-CoV-2 } & \text { Acute respiratory syndrome coronavirus 2 } \\ \text { ACC } & \text { American College of Cardiology } \\ \text { ADA } & \text { American Diabetes Association } \\ \text { AHA } & \text { American Heart Association } \\ \text { ARB } & \text { Angiotensin II receptor blocker } \\ \text { ACE2 } & \text { Angiotensin-converting-enzyme 2 } \\ \text { ACEI } & \text { Angiotensin-converting-enzyme inhibitor } \\ \text { BMI } & \text { Body mass index } \\ \text { CVD } & \text { Cardiovascular diseases } \\ \text { CSC } & \text { Chinese Society of Cardiology } \\ \text { COPD } & \text { Chronic obstructive pulmonary disease } \\ \text { CI } & \text { Confidence interval } \\ \text { COVID-19 } & \text { Coronavirus disease 2019 } \\ \text { DDG } & \text { Deutsche Diabetes Gesellschaft } \\ \text { DGK } & \text { Deutsche Gesellschaft für Kardiologie }\end{array}$

$\begin{array}{ll}\text { D\&CVD } & \text { Diabetes and Cardiovascular } \\ \text { Study Group } & \text { Disease Study Group } \\ \text { DPP-4 } & \text { Dipeptidyl peptidase-4 } \\ \text { EASD } & \text { European Association for the Study of Diabetes } \\ \text { EASO } & \text { European Association for the Study of Obesity } \\ \text { ESC } & \text { European Society of Cardiology } \\ \text { ESH } & \text { European Society of Hypertension } \\ \text { GLP-1 } & \text { Glucagon-like peptide-1 } \\ \text { HR } & \text { Hazard ratio } \\ \text { HFSA } & \text { Heart Failure Society of America } \\ \text { ICU } & \text { Intensive care unit } \\ \text { IL-6 } & \text { Interleukin-6 } \\ \text { IVM } & \text { Invasive mechanical ventilation } \\ \text { MERS-CoV } & \text { Middle East respiratory syndrome coronavirus } \\ \text { OR } & \text { Odds ratio } \\ \text { SARS-CoV } & \text { Severe acute respiratory syndrome coronavirus } \\ \text { SGLT-2 } & \text { Sodium-glucose cotransporter-2 } \\ \text { T1DM } & \text { Type 1 diabetes mellitus } \\ \text { T2DM } & \text { Type 2 diabetes mellitus }\end{array}$




\section{Introduction}

The year 2020 has thus far mainly been dominated by the emergence of a new coronavirus - severe acute respiratory syndrome coronavirus 2 (SARS-CoV-2) - which has become a global pandemic within a couple of month. By the end of August 2020 the associated respiratory disease - coronavirus disease 2019 (COVID-19) has been diagnosed in more than 23000000 individuals, resulting in more than 800000 deaths [1]. In Italy, one of the countries strongly impacted by SARS-CoV-2, total mortality for March 1 to April 4, 2020 was increased by $104.5 \%$ compared with the average number of deaths for the prior 5 years [2]. The impact on mortality rates for Italy is considerably greater than indicated by official COVID-19 deaths [3] and similar observations have been made for other European countries [4]. This might be driven by restriction in chronic and acute care opportunities implemented in the respective countries. Even with the high mortality rates it needs to be considered that in more than $80 \%$ of individuals with SARS-CoV-2 infection no or only mild symptoms can be observed [5].

Infection with SARS-CoV-2 and progression of COVID-19 is characterised by an initial infection phase, followed by a respiratory distress phase and a severe hyperinflammation state $[5,6]$. Virus infiltration is mediated via the angiotensin-converting-enzyme 2 (ACE2) receptor, which is widely expressed in several organs. Its expression by endothelial cells might enable SARS-CoV-2 to infect blood vessels and thus contribute to a wide distribution of the virus [7]. Following virus infection, host inflammatory response is amplified, which will culminate in systemic inflammation and a so called cytokine storm [6, 8]. As a result, SARS-CoV- 2 infection does not only lead to pneumonia but may also cause damage to other organs including the heart, liver and kidneys $[9,10]$. Many studies have indicated a higher incidence of COVID-19 in males compared to females. Sama and colleagues speculated that higher plasma concentrations of ACE2 in men, as observed by cohort studies might explain this discrepancy [11].

A scaled analysis of data collected by the OpenSAFELY analytic platform of more than 17000000 individuals in the UK identified factors associated with COVID-19 death [12]. A higher risk for fatal COVID-19 course was seen with increasing obesity, diabetes, severe asthma, respiratory disease, chronic heart disease, liver disease, stroke/dementia, other neurological diseases, reduced kidney function, autoimmune disease and other immunosuppressive conditions [12]. An analysis of the first described collective with COVID-19 in Germany revealed a higher rate of obesity and a history of respiratory disease in individuals with acute respiratory distress syndrome (ARDS) compared to individuals with less severe disease progression [13]. Another observational study from Germany revealed an in hospital-mortality of $22 \%$, predominantly affecting patients receiving mechanical ventilation, patients $>80$ years and those requiring dialysis [14]. The most common underlying comorbidities of COVID-19 were chronic diseases, such as obesity, diabetes, hypertension and cardiovascular diseases (CVD) [15]. We would like to highlight the impact the abovementioned chronic diseases might have on SARS-CoV-2 infection and COVID19 (see $>$ Fig. 1), which views international scientific organisations represent, and which key learnings might be of importance for the future.

\section{COVID-19, Obesity \& Diabetes}

\section{Obesity}

Obesity is considered one of the prominent risk factors for an increased severity of COVID-19. A number of retrospective studies and analyses suggest a high prevalence of obesity in COVID-19 patients [16-20]. A French study could show that the prevalence of obesity, defined by body mass index (BMI) of at least $30 \mathrm{~kg} / \mathrm{m}^{2}$ was 1.35 times $(95 \% \mathrm{Cl} 1.08-1.66)$ higher in patients with severe COVID-19 than in the general French population [16]. The prevalence of obesity in critically ill COVID-19 patients, determined by admission to intensive care units, was also higher than in the general French population [16]. Simonnet and colleagues observed high numbers of obese and overweight individuals admitted to intensive care, indicating a more severe disease progression. The median BMI of the participants who required invasive mechanical ventilation (IVM) was $31.1 \mathrm{~kg} / \mathrm{m}^{2}$, as compared to $27.0 \mathrm{~kg} / \mathrm{m}^{2}$ for those who did not require IVM [20]. In another study, COVID-19 patients with higher BMI were more likely to develop ARDS and to experience disease exacerbation [21]. A study from New York found that individuals with obesity were more likely to require acute medical care and admission to intensive care units, especially those younger than 60 years [22]. Notably, individuals with obesity had a longer hospital stay compared to non-obese COVID-19 patients [23]. Obesity does not only appear to be associated with a worse prognosis of COVID-19 but was also found to be a significant predictor for mortality [24].

Obesity has previously been determined as a risk factor for a number of virus infections, due to its underlying chronic inflammatory phenotype [25-27]. It negatively affects immunity; high levels of cytokines are prominent in obese individuals. This low-grade inflammation can result in an increased insulin resistance, further activating the pro-inflammatory cascade. Obesity is also associated with the development of dyslipidaemia, atherosclerosis, type 2 diabetes mellitus (T2DM) and hypertension, all risk factors for a more severe COVID-19 progression [28-31]. Thus, a SARS-CoV-2 induced cytokine storm exacerbates the pre-existing, obesity-associated subclinical inflammatory situation, predisposing obese individuals to an increased risk of severe COVID-19 outbreak [25]. In addition to the negative impact on inflammation, factors associated with obesity influencing mechanical ventilation may increase the severity of lower respiratory tract infection and contribute to secondary infection [26]. Furthermore, obesity causes significant changes in the mechanics of the lungs and chest wall. These make mechanical ventilation difficult and can lead to asthma-like symptoms such as dyspnoea, wheezing and hypersensitivity of the airways [32]. These symptoms can aggravate pulmonary disease due to COVID-19.

Managing COVID-19 patients with obesity on the intensive care unit can present management challenges, specifically with regard to ventilation support, vascular access and decubital skin breakdown $[33,34]$. In view of the severity of the situation, addressing obesity by improving immune modulation e. $\mathrm{g}$. by a balanced diet, mild caloric restriction and physical exercise should be recommended as preventive measures for individuals at risk [35]. 


\section{Recommendations}

The European Association for the Study of Obesity (EASO) published a position statement on the global COVID-19 pandemic [36] to advocate their commitment in supporting individuals with obesity by creating resources for health care professionals, patients and policymakers. There is currently a lack of data describing health effects and impacts of COVID-19 on obesity during lockdown, quarantine, and self-isolation, thus the EASO petitions for novel and high-impact research and support tools related to COVID-19 and obesity [36].

\section{Diabetes}

Early during the pandemic, there were indications for an increased risk of SARS-CoV-2 infection specifically for people with diabetes [37]. Reports and observational studies from China and Italy identified a high number of individuals with diabetes among hospitalised COVID-19 patients, as well as among individuals with fatal outcomes $[9,10,19,29-31,38,39]$. Further investigations then determined an increased severity of COVID-19 and mortality outcomes associated with diabetes, rather than an increased incidence $[15,37,40-46]$. It should be stated, that most observational studies did not assess prevalence of COVID-19 or its severity in people with diabetes in relation to the overall respective populations, especially not adjusted for age.

An observational study of 193 patients with severe COVID-19 showed an increased mortality rate of patients with diabetes compared to patients without diabetes ( $81.3 \%$ vs. $47.6 \%$, with an overall mortality rate of $56.0 \%$ ) [40]. Individuals with diabetes already had higher laboratory parameters at hospital admission and had more comorbidities, which might have additionally influenced severity of COVID-19 as well as mortality [40].

A retrospective longitudinal, multicentre study assessed a potential association of glycaemic control and clinical outcomes in people with T2DM and COVID-19 [47]. The study included 7337
COVID-19 patients of whom $13 \%$ had T2DM, which is in alignment with the prevalence of T2DM in China with about 10.9\% [48]. The median duration from first symptoms to hospital admission was 10 days (interquartile range [IQR], 6-19); major symptoms for both groups were similar to the general population of patients. People with T2DM had an increased need to receive medical interventions during COVID-19, and had a higher in-hospital death rate compared to control individuals. The higher occurrence of adverse outcomes in people with T2DM was associated with the level of blood glucose control. Individuals with an $\mathrm{HbA} 1 \mathrm{c}$ of $8.1 \%$ had worse laboratory characteristics and required more intense therapeutic management than individuals with an $\mathrm{HbA} 1 \mathrm{c}$ of $7.3 \%$, who were comparable to the control group with regard to most analysed parameters [47].

A retrospective observational study from the US suggested that uncontrolled hyperglycaemia might have a stronger influence on hospital length of stay and mortality than a high HbA1c. In the study, mortality rates of patients with diabetes ( $\mathrm{HbA} 1 \mathrm{c} 9.1 \%$ ) were lower than in COVID-19 patients with uncontrolled hyperglycaemia (HbA1c 5.9\%): 14.8\% vs. $41.7 \%$, respectively [49]. These data raise the question, whether high glucose variability rather than chronic hyperglycaemia are predominantly driving COVID-19 severity and mortality and whether improving glucose variability should be the focus of glycaemic management.

Another observation made by a retrospective study with Chinese individuals hospitalised with COVID-19 indicates an excessive disease severity in people with newly diagnosed diabetes compared to those with known diabetes, hyperglycaemia and normal glucose [50]. This might be in accordance with the above statements, that not only hyperglycaemia but also glycaemic variability are associated with COVID-19 outcomes. Several studies support the view that at-admission hyperglycaemia emerges as an independent factor for poor prognosis and outcome in patients with COVID-19 not only in individuals with diabetes. In hospitalised patients without

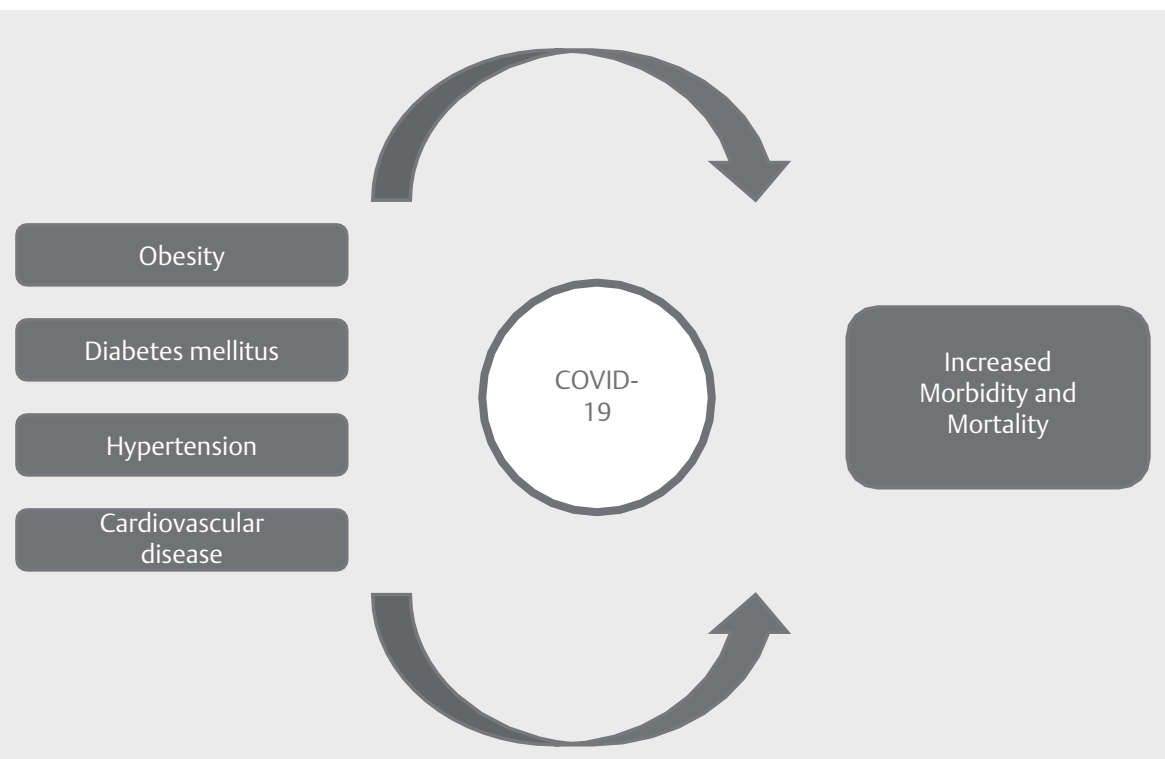

Fig. 1 Risk factors for severe disease course and mortality in patients with Covid19. 
pre-existing diabetes at-admission hyperglycaemia accounts for a 30 \% higher mortality rate. The Pisa Study suggested a bidirectional relationship between COVID-19 and hyperglycaemia mediated by an increase of ACE2 activity [51-53]. In a retrospective analysis of COVID-19 patients with T2DM $56.6 \%$ of participants had abnormal blood glucose levels, including both pre- and postprandial excursions [54]. This highlights the importance of stringent glucose management in individuals with T2DM not infected with SARSCoV-2, especially in view of the increased disease severity and mortality in individuals with uncontrolled glycaemia.

There is not only a potential interaction between diabetes and glycaemic control with COVID-19 severity and related mortality; SARS-CoV-2 infection and associated treatment options can also negatively influences blood glucose level in people with diabetes. Already in previous pandemic/epidemic incidences triggered by viruses, such as severe acute respiratory syndrome coronavirus (SARS-CoV), H1N1 influenza virus infection and Middle East respiratory syndrome coronavirus (MERS-CoV), diabetes increased the risk of complications [55-58]. It is well known that diabetes and especially hyperglycaemia concur with immune dysfunctions, such as cytokine dysregulation and inflammation [59-61]. As for obesity, it was discussed that the pro-inflammatory state, characterised by an inappropriate cytokine response could be causative for the increased severity of COVID-19 in individuals with diabetes. The additional cytokine storm induced by SARS-CoV-2 leads to ARDS, shock and rapid deterioration of COVID-19 [15]. Additionally the underlying pro-thrombotic state in people with diabetes further heightens the over-activation of the coagulation cascade in COVID19 [62]. A direct effect of SARS-CoV-2 on the pancreatic $\beta$-cells can lead to worsening of insulin resistance and insulin sensitivity. It has been shown that coronavirus infection - specifically SARS-CoV can damage islet cells of the pancreas and cause acute insulin dependent diabetes [63]. $51 \%$ of patients of a study investigating the pathogenesis of glucose intolerance, surviving SARS-CoV infection developed diabetes during hospitalisation. At 3 years of follow-up, only $5 \%$ of these patients still had diabetes, indicating that the damage of islets by SARS-CoV was transient [63]. It was discussed, that SARS-CoV-2 infection might also infect the pancreas, leading to hyperglycaemia and thereby instigating upregulation of glycosylated ACE2 in the lung and thus further virus binding and inflammation $[64,65]$.

The treatment of COVID-19 might negatively influence glycaemic control in people with diabetes. Corticosteroids, azithromycin and other therapeutics can, for example, lead to glycaemic excursions and increase the risk for dysglycaemia [66]. On the other hand, hydroxychloroquine, which has frequently been used in the treatment of COVID-19 has a positive impact on glycaemic control and is an approved glucose-lowering medication for T2DM in India [67]. Thus, dose adjustments for oral antidiabetic drugs and/or insulin might be necessary to ensure stable glycaemic profile in individuals with COVID-19 and diabetes.

The discussion on the increased severity of COVID-19 in individuals with diabetes is closely associated with aspects of therapeutic measures, e. g. the continuation or discontinuation of glucose-lowering medication. It was suggested to discontinue sodium-glucose cotransporter-2 (SGLT-2) inhibitors due to the risk of dehydration and diabetic ketoacidosis. Similarly, physicians should consider dis- continuation of metformin therapy $[68,69]$. Current evidence on pioglitazone and liraglutide does not support any changes in the ongoing medications [70]. As dipeptidyl peptidase-4 (DPP-4) is the primary receptor for MERS-CoV [71], it has been speculated whether treatment with DPP-4 inhibitors might be beneficial in context of COVID-19. An association of DPP-4 and SARS-CoV-2 has not been observed and there are currently no studies arguing for or against a positive influence of DPP-4 inhibitors in patients with COVID-19, nor any information indicating the necessity for discontinuation of treatment. Most hospitalised patient with COVID-19, especially those with respiratory distress, would require initiation of insulin therapy [68]. However, an early retrospective study suggested that long-term insulin utilisation was associated with progression to severe or critical illness or in-hospital death (adjusted odds ratio $(\mathrm{OR})=3.58$; $95 \%$ confidence interval $(\mathrm{Cl}) 1.37-9.35$ ) [72]. It is however unclear, whether this association is a direct consequence of insulin utilisation or diabetes progression. Changing therapy strategies to e. g. initiating insulin therapy should consider severity of COVID-19, nutritional status, actual glycaemic control, risk of hypoglycaemia, renal function, and drug interactions [73]. Overall, enhanced self-management, supportive healthcare services and public health measures should be implemented to minimise the risk for people with diabetes for SARS-CoV-2 infection [74].

\section{Recommendations}

In recent months, many scientific associations and societies have published opinions, statements and recommendations on how to approach the current situation - on large and small scales. The Infectious Diseases Society of America published a guideline on the treatment and management of patients with COVID-19, which is regularly updated [75]. Focusing on diabetes, the American, European and German associations (ADA, EASD and DDG), amongst others, provided platforms for health care professionals to educate themselves on a variety of topics in relation to SARS-CoV-2 and COVID-19. The ADA additionally issued a special "Diabetes and COVID-19" section in the peer-reviewed journal "Diabetes Care". No official guidelines or recommendations are available as of yet by ADA and EASD. In Germany, the DDG has published practical recommendations for adult individuals with diabetes and COVID19 [76]. The authors recommend a discontinuation of SGLT-2 inhibitors, as well as of metformin, sulfonylureas and pioglitazone in patients with fever $>38.5^{\circ} \mathrm{C}$; for glucagon-like peptide- 1 (GLP-1) receptor agonists and DDP-4 inhibitors no safety concerns are apparent, nevertheless therapy adaptations in favour of insulin should be considered in severe COVID-19 cases. Management of risk factors such as hypertension and lipids should be continued, although a close monitoring of parameters is required [76]. The DDG statement additionally provides specific recommendations and targets on glucose management in intensive care units using intravenous insulin therapy [76].

There are a number of independent recommendations and position statements available, addressing diabetes management in COVID-19 patients [77-79]. These are clearly stated as "recommendations and reflections based on expert opinions, awaiting the outcome of randomised clinical trials" [77]. People with diabetes not infected with SARS-CoV-2 should continue their diabetes management and follow means of primary prevention of COVID-19. 
- Table 1 Current key recommendations/position statements by scientific associations.

\begin{tabular}{|c|c|c|c|}
\hline $\begin{array}{l}\text { Chronic } \\
\text { disease }\end{array}$ & Scientific association & Recommendation/position statement & Reference \\
\hline \multirow[t]{4}{*}{$\begin{array}{l}\text { Diabetes } \\
\text { mellitus }\end{array}$} & DDG & $\begin{array}{l}\text { - Management of hypertension and lipids should be monitored, therapies } \\
\text { should be continued } \\
\text { - Discontinuation of metformin, sulfonylureas pioglitazone, and SGLT-2 } \\
\text { inhibitors in patients COVID-19 and fever }>38.5^{\circ} \mathrm{C} \\
\text { - No safety concerns for GLP-1 receptor agonists and DPP- } 4 \text { inhibitors } \\
\text { Therapy adaptation in favour of insulin should be considered in severe COVID-19 }\end{array}$ & [96] \\
\hline & EASD & No official guidelines or recommendations have been published & \\
\hline & ADA & No official guidelines or recommendations have been published & \\
\hline & $\begin{array}{l}\text { D\&CVD Study Group/ } \\
\text { Bornstein et al., 2020/ } \\
\text { Hartmann-Boyce et al., } 2020\end{array}$ & $\begin{array}{l}\text { - People with diabetes not infected with SARS-CoV-2 should continue their } \\
\text { diabetes management and follow primary prevention of COVID-19 }\end{array}$ & [77-79] \\
\hline \multirow[t]{3}{*}{ Hypertension } & ESC & $\begin{array}{l}\text { - ACEI/ARB treatment should not be discontinued as a consequence of a } \\
\text { SARS-CoV-2 infection } \\
\text { - Continue treatment with antihypertensive medication according to } \\
\text { ESC-ESH guideline } 2018\end{array}$ & {$[102,122]$} \\
\hline & ESH & $\begin{array}{l}\text { - Currently available data does not support a differential use of ACEI/ARBs in } \\
\text { patients with COVID-19 }\end{array}$ & [99] \\
\hline & $\begin{array}{l}\text { Joint Statement of AHA, } \\
\text { HFSA, ACC }\end{array}$ & - Continuation of ACEI/ARBs in hypertensive individuals with COVID-19 & [101] \\
\hline Obesity & & - No official guidelines or recommendations have been published & \\
\hline \multirow[t]{5}{*}{$\begin{array}{l}\text { Cardiovascular } \\
\text { disease }\end{array}$} & DGK & $\begin{array}{l}\text { - Ensure guideline recommended care of individuals with COVID-19 and } \\
\text { cardiovascular disease } \\
\text { - Continue treatment with ACEI/ARBs }\end{array}$ & [103-127] \\
\hline & ESC & $\begin{array}{l}\text { Recommendations on } \\
\text { - Strategies for diagnosing SARS-CoV-2 } \\
\text { - } \quad \text { Protective measures for health care personnel and patients in cardiology } \\
\text { - } \quad \text { Triage systems (reorganisation and redistribution) } \\
\text { - } \quad \text { Diagnosis of cardiovascular conditions in COVID-19 patients } \\
\text { - } \quad \text { Categorisation of emergency/urgency of invasive procedures } \\
\text { - } \quad \text { Management/treatment pathways } \\
\text { Patient information }\end{array}$ & [122] \\
\hline & ACC & No official guidelines or recommendations have been published & \\
\hline & $\mathrm{AHA}$ & No official guidelines or recommendations have been published & \\
\hline & CSC & $\begin{array}{l}\text { General recommendations on } \\
\text { 1. Risk assessment } \\
\text { 2. Protection of patients and medical staff } \\
\text { 3. Adapting measures tailored to specific local epidemic situations } \\
\text { 4. Consider conservative medical treatment as a top priority } \\
\text { Recommendations on medical therapyRecommendations on strategies of } \\
\text { cardiovascular intervention } \\
\text { 1. Conditions warranting invasive intervention } \\
\text { 2. In-hospital transport of patients undergoing interventional procedures } \\
\text { 3. Protection in cardiac catheterization labs } \\
\text { 4. Perioperative management } \\
\text { Other recommendations } \\
\text { 1. Optimising laboratory testing } \\
\text { 2. Referral between hospital } \\
\text { 3. Telemedicine } \\
\text { Psychological intervention }\end{array}$ & [123] \\
\hline $\begin{array}{l}\text { Acute respirat } \\
\text { Heart Associat } \\
\text { Coronavirus di } \\
\text { cular Disease } \\
\text { Society of Car } \\
\text { Sodium-gluco }\end{array}$ & $\begin{array}{l}\text { rome coronavirus } 2 \text { (SARS- } \\
\text { A); Angiotensin II receptor } \\
19 \text { (COVID-19); Deutsche } \\
\text { oup (D\&CVD Study Group) } \\
\text { ESC); European Society of } \\
\text { Isporter-2 (SGLT-2). }\end{array}$ & $\begin{array}{l}\text {; American College of Cardiology (ACC); American Diabetes Association (ADA); } \\
\text { (ARB); Angiotensin-converting-enzyme inhibitor (ACEI);Chinese Society of Car } \\
\text { es Gesellschaft (DDG); Deutsche Gesellschaft für Kardiologie (DGK); Diabetes ar } \\
\text { tidyl peptidase-4 (DPP-4); European Association for the Study of Diabetes (EASI } \\
\text { ension (ESH); Glucagon-like peptide-1 (GLP-1); Heart Failure Society of America }\end{array}$ & $\begin{array}{l}\text { ican } \\
\text { y (CSC); } \\
\text { rdiovas- } \\
\text { ropean } \\
\text { A); }\end{array}$ \\
\hline
\end{tabular}


Recommendations for individuals with diabetes and COVID-19 are in accordance with those provided by the DDG: consideration of discontinuation of potential metabolically interfering medications such as SGLT-2 inhibitors and metformin [77-79]. Decisions on therapy adaptations should only be made in concert with the respective health care professional. Recommendations are summarised in $>$ Table $\mathbf{1}$.

\section{COVID-19, Hypertension \& Cardiovascular Disease}

\section{Hypertension}

Similar to the abovementioned conditions, hypertension is commonly reported as one of the most common underlying comorbidity of COVID-19 [15, 80]. This might in part be due to the strong association of hypertension with older age as well as other comorbidities. Adjusting for these confounders however indicates a direct association of hypertension with the increased severity of COVID-19 and an increased COVID-19-related mortality. Also similar to the abovementioned conditions, prevalence of hypertension in the overall number of SARS-CoV-2 infected individuals was comparable to the respective country-specific prevalence (e. g. China $26.6 \%$, Italy $25.9 \%[81,82])$.

A number of retrospective studies as well as propensity score matched and meta-analyses showed that hypertension could significantly increase severity and fatality of COVID-19 [83-90]. In a retrospective observational study, COVID-19 patients with hypertension had a higher mortality rate ( $24.8 \%$ vs. $15.2 \%$ ), a higher proportion of severe patients (63.7\% vs. $42.1 \%$ ), a higher proportion of patients receiving non-invasive mechanical ventilation $(16.8 \%$ vs. $7.6 \%$ ), and a higher proportion of patients transferred to the intensive care unit (ICU) (23.9\% vs. $12.2 \%$ ). Adjusting for confounding effects of other complications, the increased risk for COVID-19 severity and ICU admission was still observed, whereas for mortality and length of hospital stay no significant difference remained between individuals with or without hypertension [84]. A recent meta-analysis, published as a Letter to the Editor, summarised that the prevalence of hypertension in patients with severe COVID-19 progression as significantly higher than in non-severe patients [85]. In another meta-analysis, hypertension was associated with increased risk for poor outcomes in patients with COVID-19. Adjusting for confounders, such age, gender, presence of CVD, diabetes or chronic obstructive pulmonary disease (COPD) did not affect the association [86]. A propensity-score matched analysis including COVID-19 patients from Wuhan showed that patients with hypertension had significantly higher risk of death (hazard ratio (HR) 2.679;95\% Cl [1.237-5.805]; $\mathrm{P}=0.012 ;$ ) [87].

It was discussed, that hypertension is a risk factor for severe COVID-19 either due to a strong relation to age or due to potential end-organ damage in hypertensive individuals [91]. As mentioned above, many studies and meta-analysis were however able to adjust for confounding effects such as age and CVD, questioning the abovementioned theory $[84,86,92]$. On the other hand, there has been a focus on a potential association of inflammation and immunity with hypertension (and CVD) $[93,94]$ which, similarly to obesity and diabetes, might contribute to the increased risk for severe
COVID-19. For example, immune-inflammation responses in hypertension are mainly regulated by interleukin-6 (IL-6), which is strongly linked to clinical outcomes of COVID-19 [95, 96].

\section{ACEI/ARBs}

As for diabetes and CVD, it was discussed for hypertension that the higher risk for COVID-19 severity is associated with ACE2 and a dysregulation of the renin-angiotensin system (RAS) cascade [97]. Thus it was questioned whether treatment with ACE inhibitors (ACEI)/ angiotensin II receptor blockers (ARBs) might be harmful in hypertensive patients with COVID-19. A retrospective study from China compared all-cause mortality of individuals treated with or without ACEI/ARBs. Individuals with COVID-19 and coexisting hypertension had lower risk of all-cause mortality when treated with ACEI/ARB [98].

\section{Recommendations}

All major scientific societies have published position statements, specifically addressing the use of ACEI/ARBs [99-104]. The European Society of Hypertension has generated a review on the relation of hypertension, RAS and the risk for lower respiratory tract infections and lung injury [100]. They strongly highlight that currently available data do not support a differential use of ACEI/ARBs in patients with COVID-19. Decisions on discontinuation in patients with severe symptoms, sepsis or haemodynamic instability should be made on a case-to-case basis [99]. The American Heart Association , the Heart Failure Society of America and the American College of Cardiology issued a joint statement, strongly recommending continuation of ACEI/ARBs in hypertensive individuals with COVID-19 [101]. The European Society of Cardiology stated in March 2020 that speculations on the safety of ACEI/ARB treatment in relation to COVID-19 are not based on scientific evidence, and should thus not be discontinued as a consequence of a SARS-CoV-2 infection [102].

\section{Cardiovascular Disease}

In line with the abovementioned risk factors, CVD such as coronary heart disease, myocardial infarction and heart failure are associated with in increased COVID-19 severity $[37,105,106]$. Similar to obesity, diabetes and hypertension, many studies and reports show increased rates of mortality in patients with COVID-19 and a preexisting CVD [106]. In one retrospective cohort study, fatal cases had a higher rate of e. g. coronary heart disease compared to survivors: 24 vs. $1 \%$, respectively [107]. In another small retrospective study, CVD was more prevalent in fatal COVID-19 cases than in survivors: 13 of 68 vs. 0 of 82, respectively [108]. A meta-analysis suggested a fivefold higher risk of mortality in individuals with CVD compared to COVID-19 patients without CVD (unadjusted OR 4.85, $\mathrm{p}<0.001 ; 95 \% \mathrm{Cl} 3.06-7.70$; [109]). Another study could show that the risk of severe disease progression was higher in individuals with CVD compared to those without ( 27.8 vs. $8.8 \%$ ). Mortality rates showed a similar range (22.2 vs. $9.8 \%$ ) [110].

In addition to being a highly associated comorbidity for COVID19 severity, cardiac injury is a common condition in individuals infected with SARS-CoV-2 [111-114]. Heart tissue is frequently affected by viral infections, resulting in e. $\mathrm{g}$. myocarditis, acute coronary syndromes or heart failure $[107,115]$. Studies from China 
report an increased morbidity and mortality in individuals with COVID-19 and myocarditis [105, 111, 113]. For example, more individuals with cardiac injury required non-invasive or invasive mechanical ventilation than those without cardiac injury. Also mortality rates are higher in patients with COVID-19 and a cardiac injury than in those without (42 of 82 [51.2\%] vs. 15 of 334 [4.5\%]; $\mathrm{P}<0.001$ ) [113]. Autopsy reports could show that more than half of the investigated individuals with fatal COVID-19 had a viral presence in the myocardium, which could explain the cardiac injuries frequently observed in COVID-19 patients [116]. Prior experience with virus induced myocarditis suggests a direct cellular response to viral entry and the innate immune response resulting in myocardial necrosis [117]. Aside from a viral presence in cardiomyocytes, it can be speculated that myocardial injuries are a result of the inflammatory response to SARS-CoV-2 infection and/or microvascular damage caused by intravascular coagulation and thrombosis $[114,118]$.

The long-term effects of COVID-19 on individuals cannot be estimated yet. It is likely to assume that cardiac injury might persist, thus increasing the risk for future CVD $[119,120]$. Long-term follow-up studies with SARS-CoV survivors for example indicated a high rate of morbidities 12 years after recovery, with e. g. $44 \%$ having abnormalities in the cardiovascular system [121].

\section{Recommendations}

The European Society of Cardiology has provided guidance on the diagnosis and management of CVD during the COVID-19 pandemic, strongly highlighting the preliminary nature of the document and the lack of evidence-based treatment of SARS-CoV-2 infections. The guidance reviews the association between CVD and COVID-19 and provides detailed recommendations on the management and diagnosis of CVD in current circumstances [122]. Similarly, the Chinese Society of Cardiology published an expert consensus on principles of clinical management of individuals with CVD during the COVID-19 pandemic [123]. They provide insights on general principles such as risk assessment and protection of patients and medical staff, as well as on medical therapies, cardiovascular interventions and the introduction of telemedicine to support guidance of individuals with CVD [123]. The American Heart Association provides a number of resources on their website, where physicians and people with CVD can inform themselves about e. $\mathrm{g}$. managing blood pressure [124], while the American College of Cardiology is currently working on a Clinical Guidance for Global Cardiovascular Clinicians [125]. A consensus statement by physicians from Australia and New Zealand emphasises the "importance of maintaining contact with patients by primary care physicians" to avoid delayed intervention and adequately manage individuals with CVD e. g. with regard to medication [126]. Statements from national scientific associations such as the Deutsche Gesellschaft für Kardiologie (DGK) highlight the necessity to concentrate on guideline-recommended care of individuals with cardiovascular disease [127]. This includes a continuation of therapies such as ACEI / ARB [103]

\section{Practical Aspects}

The current situation provides a major challenge for routine care for chronic diseases. Regular consultations were limited, disease management was mostly reduced to a minimum. A study from the US showed a decrease in $\mathrm{HbA} 1 \mathrm{c}$ testing volume during March and April 2020 [128]. Although some conversion was observed in the following weeks, this might have resulted in an increase in $\mathrm{HbA} 1 \mathrm{C}$ $[129,130]$. In contrast to the abovementioned study, evaluations of glycaemia in individuals with type 1 diabetes mellitus (T1DM) as well as T2DM during lockdown in Italy showed a stable or even improved glycaemic control [131-133]. Although major cutbacks in care provided to people with chronic diseases were necessary, possibilities to exercise were limited and severe psychological stress imposed by the overall situation, people with diabetes apparently were able to focus on diabetes management [131, 132]. Additionally it was suggested, that the knowledge that diabetes can worsen the outcomes of COVID-19 might have contributed to a more compliant diabetes management $[131,132]$.

\section{Delay in medical care and practical implications}

An analysis by the Department of Veteran Affairs in the US evaluated the changes in hospital admissions, treatment of emergency conditions and cancelled elective procedures during the first 16 weeks of 2019 and 2020 [134]. The number of patients admitted to hospital decreased by more than $40 \%$ from Jan-March 2020 compared to March-April 2020. A similar decrease was not observed for hospital admissions during the same time in 2019 [134]. For Italy even stronger decreases have been observed for paediatric emergency department visits- ranging from $73 \%$ to $88 \%$ compared to the same period in 2018 and 2019 [135]. In Germany hospital admissions were reduced by $13 \%$ in the first 22 weeks of 2020 compared to 2019 , with a reduction of $38 \%$ in week 14 , when COVID19 rates were highest [136]. Several examples of delayed hospital admission provided by the study authors emphasize the risk these delays pose for the patients, e. g. intensive care admission after delayed diagnosis of T1DM, death in consequence of acute-onset leukaemia and others [135]. Similarly, German diabetes centre reported an increase in diabetic ketoacidosis in children at the time of diabetes diagnosis March to May 2020 compared to previous years. This observation might be explained by the decreased availability of medical services during lockdown, as well as fear for approaching health care institutions [137].

In addition to the consistent decrease in medical care the COVID-19 pandemic also has indirect consequences on individuals with chronic and/or acute CVD. One study from the US for example reported a $40 \%$ reduction in ST-segment elevation myocardial infarction activations [138], in another weekly rates of hospitalization for acute myocardial infarction were reduced by $48 \%$ [139]. Similar findings were observed in a study from northern Italy [140]. In France, a population-based, observational study revealed a significant increase in out-of-hospital cardiac arrest between March and April 2020 compared to previous years from 13.42 (95\% $\mathrm{Cl} 12 \cdot 77-14 \cdot 07)$ to $26 \cdot 64(25 \cdot 72-27 \cdot 53)$ per million inhabitants $(p<0 \cdot 0001)$ [141]. It was discussed that lockdown and movement restrictions imposed in France as well as a reluctance of patients to call emergency services and visit hospitals are causative for this prominent increase [141]. 


\section{Long-term consequences and opportunities}

A high number of individuals recently recovered from SARS-CoV-2 infection appears to have had cardiac involvement (78\%) and ongoing myocardial inflammation (60\%), irrespective of pre-existing comorbidities and course of COVID-19 [142]. The insights provided by this study are of great importance with regard to a potentially considerable burden of inflammatory disease in the overall population. Although the results need to be verified for a larger cohort the implications for upcoming challenges remain.

Not only the physical health aspects of SARS-CoV-2 infection, but also the mental strain the COVID-19 pandemic has put on the population will require continued follow-up. According to a survey among the UK Household Longitudinal Study cohort the population prevalence of clinically significant levels of mental distress increased from $18.9 \%$ in 2018/2019 to $27.3 \%$ in April 2020. This increase was especially prominent in individuals between the age of 18 and 34 years, and in people living with young children [143]. The survey might be indicative of the early emotional response of individuals towards the COVID-19 pandemic and associated lockdown, it is unclear whether people have adjust to the current situation, stabilizing their psychological well-being [143]. The mental strain of this challenging situation should however be acknowledge and be met with appropriately resourced services.

The COVID-19 pandemic is a challenge not only for every individual that has to take regular precautions such as social distancing, but more so for people with chronic diseases and every health care system. Individuals with chronic diseases are advised to continue their medication unless explicitly informed by their physician to do otherwise. Scientific societies have published recommendations in their respective fields to advice physicians and patients in their day-to-day disease management [144]. The abovementioned decline in individuals presenting to emergency units indicates a requirement for an adaptation of health care services, focusing on telemedical support. Thus, the current situation might presents itself as an opportunity to considerably expand the use of telemedicine in the management of chronic diseases. An online survey targeted at health care professionals (202 participants from 47 countries) suggests. They reported a change from in-person routine care to virtual communication, with diabetes, COPD, and hypertension being the most impacted conditions [145].

\section{Gaps in Knowledge}

The impact SARS-CoV-2 and COVID-19 already have had on the individual as well as on health care systems is hardly measureable. Scientific, medical and economic policy makers have been working nonstop to handle the situation as best and straightforward as possible. Trying to understand both virus and resulting disease have been the main focus of scientists all around the world. As of August 2020 the number of publications listed on PubMed NCBI just on COVID-19 is higher than 43000 . Focusing on observational studies and case reports in peer-reviewed publications provides first insights in mechanisms of action, risk factors for disease progression and therapeutical approaches. Nevertheless many open questions remain and can only be answered in the long run e. g.: how does SARS-CoV-2 infection influence the immune system of individuals? What are the long term consequences of COVID-19? How did the pandemic affect medical care of chronic diseases? Which measures to contain the virus were most effective and how did they affect medical care or mental health? What have we learned with regard to telemedicine and remote care? With increasing numbers of infections these questions remain of great importance and need to be considered when discussing how to proceed in managing this unique situation. The "Lean European Open Survey on SARS-CoV-2 infected patients" (LEOSS database and research platform, trying to uniformly record confirmed cases, might be a first step in establishing an evidence base for best practice in clinical management [146].

\section{Conclusion}

The numbers of SARS-CoV-2 infections are still increasing globally. This pandemic is far from over, thus adapting daily management of chronic diseases to this "new normal" is of the utmost importance. The association of e.g. cardiovascular comorbidities, such as obesity, diabetes mellitus, hypertension and cardiovascular disease with a higher risk for morbidities and mortality when infected with SARS-CoV-2 highlights the responsibilities of health care professionals and health care systems in providing adequate care for individuals with chronic diseases.

\section{Funding}

The creation of this publication was supported by AstraZeneca $\mathrm{GmbH}$.

\section{Conflict of Interest}

DMW receives honoraria for advisory boards and speaker bureaus from Amarin, Amgen, AstraZeneca, Boehringer Ingelheim $\mathrm{GmbH}$, Daiichi-Sankyo, Lilly, Novo Nordisk, MSD, Novartis, and Sanofi. NM, MD and KF do not have any conflict of interest with regard to this publication. OS is founder and director of Sciarc $\mathrm{GmbH}$ (Baierbrunn, Germany) and received honoraria as an advisor from Abbott, AstraZeneca, Bayer, Boehringer Ingelheim, Eli Lilly, Mundipharma, Novo Nordisk, Roche Diabetes Care and Sanofi.

\section{References}

[1] World Health Organization. WHO coronavirus disease (COVID-19) dashboard. In. Geneva; 2020

[2] Rizzo M, Foresti L, Montano N. Comparison of Reported Deaths From COVID-19 and Increase in Total Mortality in Italy. JAMA Internal Medicine 2020, doi:10.1001/jamainternmed.2020.2543

[3] Mannucci E, Nreu B, Monami M. Factors associated with increased all-cause mortality during the COVID-19 pandemic in Italy. Int J Infect Dis 2020, doi:10.1016/j.ijid.2020.06.077

[4] Vestergaard LS, Nielsen J, Richter L et al. Excess all-cause mortality during the COVID-19 pandemic in Europe - preliminary pooled estimates from the EuroMOMO network, March to April 2020. Eurosurveillance 2020; 25: 2001214. DOI:10.2807/1560-7917.ES.2020.25.26.2001214

[5] Wu Z, McGoogan JM. Characteristics of and Important Lessons From the Coronavirus Disease 2019 (COVID-19) Outbreak in China: Summary of a Report of 72314 Cases From the Chinese Center for Disease Control and Prevention. Jama 2020, doi:10.1001/jama.2020.2648 
[6] Böhm M, Frey N, Giannitsis E et al. Coronavirus Disease 2019 (COVID-19) and its implications for cardiovascular care: expert document from the German Cardiac Society and the World Heart Federation. Clin Res Cardiol 2020; 1-14. DOI: 10.1007/s00392-020-01656-3

[7] Varga Z, Flammer A], Steiger $P$ et al. Endothelial cell infection and endotheliitis in COVID-19. The Lancet 2020; 395: 1417-1418. DOI: 10.1016/S0140-6736(20)30937-5

[8] Channappanavar R, Perlman S. Pathogenic human coronavirus infections: causes and consequences of cytokine storm and immunopathology. Semin Immunopathol 2017; 39: 529-539. DOI: 10.1007/s00281-017-0629-x

[9] Huang C, Wang Y, Li X et al. Clinical features of patients infected with 2019 novel coronavirus in Wuhan, China. Lancet (London, England) 2020; 395: 497-506. DOI: 10.1016/s0140-6736(20)30183-5

[10] Wang D, Hu B, Hu C et al. Clinical Characteristics of 138 Hospitalized Patients With 2019 Novel Coronavirus-Infected Pneumonia in Wuhan, China. Jama 2020; 323: 1061-1069. DOI: 10.1001/ jama.2020.1585

[11] Sama IE, Ravera A, Santema BT et al. Circulating plasma concentrations of angiotensin-converting enzyme 2 in men and women with heart failure and effects of renin-angiotensin-aldosterone inhibitors. European Heart Journal 2020; 41: 1810-1817. DOI: 10.1093/ eurheartj/ehaa373

[12] Williamson EJ, Walker A], Bhaskaran $\mathrm{K}$ et al. OpenSAFELY: factors associated with COVID-19 death in 17 million patients. Nature 2020, doi:10.1038/s41586-020-2521-4

[13] Dreher M, Kersten A, Bickenbach J et al. The Characteristics of 50 Hospitalized COVID-19 Patients With and Without ARDS. Dtsch Arztebl International 2020; 117: 271-278. DOI: 10.3238/arztebl.2020.0271

[14] Karagiannidis C, Mostert C, Hentschker C et al. Case characteristics, resource use, and outcomes of 10021 patients with COVID-19 admitted to 920 German hospitals: an observational study. The Lancet. Respiratory Medicine 2020, doi:10.1016/S22132600(20)30316-7

[15] Guo W, Li M, Dong Y et al. Diabetes is a risk factor for the progression and prognosis of COVID-19. Diabetes/metabolism research and reviews 2020; e3319. DOI: 10.1002/dmrr.3319

[16] Caussy C, Pattou F, Wallet F et al. Prevalence of obesity among adult inpatients with COVID-19 in France. The lancet Diabetes \&. endocrinology 2020; 8: 562-564. DOI: 10.1016/s22138587(20)30160-1

[17] Chen Q, Zheng Z, Zhang C et al. Clinical characteristics of 145 patients with corona virus disease 2019 (COVID-19) in Taizhou, Zhejiang, China. Infection 2020; 1-9. DOI: 10.1007/s15010-02001432-5

[18] Mahase E. Covid-19: most patients require mechanical ventilation in first $24 \mathrm{~h}$ of critical care. BMJ (Clinical research ed) 2020; 368: m1201. DOI: $10.1136 /$ bmj.m1201

[19] Bhatraju PK, Ghassemieh B], Nichols M et al. Covid-19 in Critically III Patients in the Seattle Region - Case Series. New England Journal of Medicine 2020; 382: 2012-2022. DOI: 10.1056/NEJMoa2004500

[20] Simonnet A, Chetboun M, Poissy J et al. High Prevalence of Obesity in Severe Acute Respiratory Syndrome Coronavirus-2 (SARS-CoV-2) Requiring Invasive Mechanical Ventilation. Obesity (Silver Spring) 2020; 28: 1195-1199. DOI: 10.1002/oby.22831

[21] Cai SH, Liao W, Chen SW et al. Association between obesity and clinical prognosis in patients infected with SARS-CoV-2. Infect Dis Poverty 2020; 9: 80. DOI: 10.1186/s40249-020-00703-5

[22] Lighter J, Phillips M, Hochman S et al. Obesity in patients younger than 60 years is a risk factor for Covid- 19 hospital admission. Clin Infect Dis 2020; ciaa415. DOI: 10.1093/cid/ciaa415
[23] Gao F, Zheng KI, Wang XB et al. Obesity Is a Risk Factor for Greater COVID-19 Severity. Diabetes Care 2020; 43: e72-e74. DOI: 10.2337/ dc20-0682

[24] Pettit NN, MacKenzie EL, Ridgway J et al. Obesity is Associated with Increased Risk for Mortality Among Hospitalized Patients with COVID-19. Obesity (Silver Spring) 2020, doi:10.1002/oby.22941

[25] Alberca RW, Oliveira LM, Branco A et al. Obesity as a risk factor for COVID-19: an overview. Crit Rev Food Sci Nutr 2020; 1-15. DOI: 10.1080/10408398.2020.1775546

[26] Han JM, Patterson SJ, Speck M et al. Insulin inhibits IL-10-mediated regulatory T cell function: implications for obesity. J Immunol 2014; 192: 623-629. DOI: 10.4049/jimmunol.1302181

[27] Andersen C], Murphy KE, Fernandez ML. Impact of Obesity and Metabolic Syndrome on Immunity. Advances in nutrition (Bethesda, Md) 2016; 7: 66-75. DOI: 10.3945/an.115.010207

[28] Wang T, Du Z, Zhu F et al. Comorbidities and multi-organ injuries in the treatment of COVID-19. Lancet (London, England) 2020; 395: e52 DOI: 10.1016/s0140-6736(20)30558-4

[29] Yang X, Yu Y, Xu J et al. Clinical course and outcomes of critically ill patients with SARS-CoV-2 pneumonia in Wuhan, China: A singlecentered, retrospective, observational study. The Lancet Respiratory Medicine 2020; 8: 475-481. DOI: 10.1016/S2213-2600(20)30079-5

[30] Guan W-j, Ni Z-y, Hu Y et al. Clinical Characteristics of Coronavirus Disease 2019 in China. New England Journal of Medicine 2020; 382: 1708-1720. DOI: 10.1056/NEJMoa2002032

[31] Zhang J-j, Dong X, Cao Y-y et al. Clinical characteristics of 140 patients infected with SARS-CoV-2 in Wuhan, China. Allergy 2020; DOI: $10.1111 /$ all. 14238

[32] Dixon AE, Peters U. The effect of obesity on lung function. Expert Rev Respir Med 2018; 12: 755-767. DOI: 10.1080/17476348.2018.1506331

[33] Chiappetta S, Sharma AM, Bottino V et al. COVID-19 and the role of chronic inflammation in patients with obesity. Int J Obes (Lond) 2020; 1-3. DOI: 10.1038/s41366-020-0597-4

[34] Selim B], Ramar K, Surani S. Obesity in the intensive care unit: risks and complications. Hosp Pract (1995) 2016; 44: 146-156. DOI: $10.1080 / 21548331.2016 .1179558$

[35] Luzi L, Radaelli MG. Influenza and obesity: its odd relationship and the lessons for COVID-19 pandemic. Acta Diabetologica 2020; 57: 759-764. DOI: 10.1007/s00592-020-01522-8

[36] Frühbeck G, Baker JL, Busetto L et al. European Association for the Study of Obesity Position Statement on the Global COVID-19 Pandemic. Obesity Facts 2020; 13: 292-296. DOI: $10.1159 / 000508082$

[37] Li B, Yang J, Zhao F et al. Prevalence and impact of cardiovascular metabolic diseases on COVID-19 in China. Clin Res Cardiol 2020; 109: 531-538. DOI: 10.1007/s00392-020-01626-9

[38] Onder G, Rezza G, Brusaferro S. Case-Fatality Rate and Characteristics of Patients Dying in Relation to COVID-19 in Italy. Jama 2020; 323: 1775-1776. DOI: 10.1001/jama.2020.4683

[39] Wu C, Chen X, Cai Y et al. Risk Factors Associated With Acute Respiratory Distress Syndrome and Death in Patients With Coronavirus Disease 2019 Pneumonia in Wuhan, China. JAMA internal medicine 2020; e200994. DOI: 10.1001/jamainternmed.2020.0994

[40] Yan Y, Yang Y, Wang F et al. Clinical characteristics and outcomes of patients with severe covid-19 with diabetes. BMJ open diabetes research \& care 2020; 8 : DOI: 10.1136/bmjdrc-2020-001343

[41] Roncon L, Zuin M, Rigatelli G et al. Diabetic patients with COVID-19 infection are at higher risk of ICU admission and poor short-term outcome. J Clin Virol 2020; 127: 104354. DOI: 10.1016/j. jcv.2020.104354 
[42] Chung SM, Lee YY, Ha E et al. The Risk of Diabetes on Clinical Outcomes in Patients with Coronavirus Disease 2019: A Retrospective Cohort Study. Diabetes Metab J 2020; 44: 405-413. DOI: 10.4093/dmj.2020.0105

[43] Fadini GP, Morieri ML, Longato E et al. Prevalence and impact of diabetes among people infected with SARS-CoV-2. Journal of Endocrinological Investigation 2020; 43: 867-869. DOI: 10.1007/ s40618-020-01236-2

[44] Mantovani A, Byrne CD, Zheng MH et al. Diabetes as a risk factor for greater COVID-19 severity and in-hospital death: A meta-analysis of observational studies. Nutrition, Metabolism, and Cardiovascular Diseases : NMCD 2020, doi:10.1016/j.numecd.2020.05.014

[45] Wu ZH, Tang Y, Cheng Q. Diabetes increases the mortality of patients with COVID-19: a meta-analysis. Acta Diabetologica 2020; 1-6. DOI: 10.1007/s00592-020-01546-0

[46] Wu J, Zhang J, Sun X et al. Influence of diabetes mellitus on the severity and fatality of SARS-CoV-2 (COVID-19) infection. Diabetes, Obesity \& Metabolism 2020, doi:10.1111/dom. 14105

[47] Zhu L, She ZG, Cheng X et al. Association of Blood Glucose Control and Outcomes in Patients with COVID-19 and Pre-existing Type 2 Diabetes. Cell Metabolism 2020, doi:10.1016/j.cmet.2020.04.021

[48] Wang L, Gao P, Zhang M et al. Prevalence and Ethnic Pattern of Diabetes and Prediabetes in China in 2013. Jama 2017; 317 : 2515-2523. DOI: 10.1001/jama.2017.7596

[49] Bode B, Garrett V, Messler J et al. Glycemic Characteristics and Clinical Outcomes of COVID-19 Patients Hospitalized in the United States. J Diabetes Sci Technol 2020; 1932296820924469. DOI: $10.1177 / 1932296820924469$

[50] Li H, Tian S, Chen T et al. Newly diagnosed diabetes is associated with a higher risk of mortality than known diabetes in hospitalized patients with COVID-19. Diabetes, Obesity \&. Metabolism 2020, doi:10.1111/dom.14099

[51] Cariou B, Hadjadj S, Wargny M et al. Phenotypic characteristics and prognosis of inpatients with COVID-19 and diabetes: the CORONADO study. Diabetologia 2020; 1-16. DOI: 10.1007/s00125-020-05180-x

[52] Coppelli A, Giannarelli R, Aragona M et al. Hyperglycemia at Hospital Admission Is Associated With Severity of the Prognosis in Patients Hospitalized for COVID-19: The Pisa COVID-19 Study. Diabetes Care 2020; dc201380. DOI: $10.2337 /$ dc20-1380

[53] Singh AK, Singh R. At-admission hyperglycemia is consistently associated with poor prognosis and early intervention can improve outcomes in patients with COVID-19. Diabetes \& Metabolic Syndrome: Clinical Research \& Reviews 2020, doi:10.1016/j. dsx.2020.08.034

[54] Zhou J, Tan J. Diabetes patients with COVID-19 need better blood glucose management in Wuhan, China. Metabolism: Clinical and Experimental 2020; 107: 154216. DOI: 10.1016/j.metabol.2020.154216

[55] Allard R, Leclerc P, Tremblay C et al. Diabetes and the severity of pandemic influenza A (H1N1) infection. Diabetes Care 2010; 33: 1491-1493. DOI: $10.2337 / \mathrm{dc} 09-2215$

[56] Booth CM, Matukas LM, Tomlinson GA et al. Clinical features and short-term outcomes of 144 patients with SARS in the greater Toronto area. Jama 2003; 289: 2801-2809. DOI: 10.1001/ jama.289.21.JOC30885

[57] Yang JK, Feng Y, Yuan MY et al. Plasma glucose levels and diabetes are independent predictors for mortality and morbidity in patients with SARS. Diabet Med 2006; 23: 623-628. DOI: 10.1111/j.1464-5491.2006.01861.x

[58] Nassar MS, Bakhrebah MA, Meo SA et al. Middle East Respiratory Syndrome Coronavirus (MERS-CoV) infection: epidemiology, pathogenesis and clinical characteristics. Eur Rev Med Pharmacol Sci 2018; 22: 4956-4961. DOI: 10.26355/eurrev_201808_15635
[59] Ilyas R, Wallis R, Soilleux E] et al. High glucose disrupts oligosaccharide recognition function via competitive inhibition: a potential mechanism for immune dysregulation in diabetes mellitus. Immunobiology 2011; 216: 126-131. DOI: 10.1016/j.imbio.2010.06.002

[60] Geerlings SE, Hoepelman AI. Immune dysfunction in patients with diabetes mellitus (DM). FEMS Immunol Med Microbiol 1999; 26 : 259-265. DOI: 10.1111/j.1574-695X.1999.tb01397.x

[61] Pearson-Stuttard J, Blundell S, Harris T et al. Diabetes and infection: assessing the association with glycaemic control in population-based studies. The lancet Diabetes \& endocrinology 2016; 4: 148-158. DOI: 10.1016/s2213-8587(15)00379-4

[62] Hussain A, Bhowmik B, do Vale Moreira NC. COVID-19 and diabetes: Knowledge in progress. Diabetes research and clinical practice 2020; 162: 108142-108142. DOI: 10.1016/j.diabres.2020.108142

[63] Yang JK, Lin SS, Ji X] et al. Binding of SARS coronavirus to its receptor damages islets and causes acute diabetes. Acta Diabetologica 2010; 47: 193-199. DOI: 10.1007/s00592-009-0109-4

[64] Brufsky A. Hyperglycemia, hydroxychloroquine, and the COVID-19 pandemic. J Med Virol 2020, doi:10.1002/jmv.25887

[65] Bornstein SR, Dalan R, Hopkins D et al. Endocrine and metabolic link to coronavirus infection. Nature Reviews. Endocrinology 2020; 16: 297-298. DOI: 10.1038/s41574-020-0353-9

[66] Pal R, Bhadada SK. COVID-19 and diabetes mellitus: An unholy interaction of two pandemics. Diabetes \& Metabolic Syndrome 2020; 14: 513-517. DOI: 10.1016/j.dsx.2020.04.049

[67] Kumar V, Singh MP, Singh AP et al. Efficacy and safety of hydroxychloroquine when added to stable insulin therapy in combination with metformin and glimepiride in patients with type 2 diabetes compare to sitagliptin. 2018 2018; 7: 6. DOI: 10.18203/2319-2003.ijbcp20183930

[68] Singh AK, Gupta R, Ghosh A et al. Diabetes in COVID-19: Prevalence, pathophysiology, prognosis and practical considerations. Diabetes \& Metabolic Syndrome 2020; 14: 303-310. DOI: 10.1016/j.dsx.2020.04.004

[69] Drucker DJ. Coronavirus Infections and Type 2 Diabetes-Shared Pathways with Therapeutic Implications. Endocrine reviews 2020; 41 : DOI: 10.1210/endrev/bnaa011

[70] Pal R, Bhadada SK. Should anti-diabetic medications be reconsidered amid COVID-19 pandemic? Diabetes Research and Clinical Practice 2020; 163: 108146. DOI: https://doi.org/10.1016/j.diabres.2020.108146

[71] Song Z, Xu Y, Bao L et al. From SARS to MERS, Thrusting Coronaviruses into the Spotlight. Viruses 2019; 11 : DOI: 10.3390/v11010059

[72] Chen Y, Yang D, Cheng B et al. Clinical characteristics and outcomes of patients with diabetes and COVID-19 in association with glucose-lowering medication. Diabetes Care 2020; 43: 1399-1407. DOI: $10.2337 / \mathrm{dc} 20-0660$

[73] Apicella M, Campopiano MC, Mantuano M et al. COVID-19 in people with diabetes: understanding the reasons for worse outcomes. The lancet Diabetes \& Endocrinology 2020, doi:10.1016/s22138587(20)30238-2

[74] Katulanda P, Dissanayake HA, Ranathunga I et al. Prevention and management of COVID-19 among patients with diabetes: An appraisal of the literature. Diabetologia 2020; 63: 1440-1452. DOI: 10.1007/s00125-020-05164-x

[75] Bhimraj A, Morgan RL, Shumaker AH et al. Infectious Diseases Society of America Guidelines on the Treatment and Management of Patients with COVID-19. Clin Infect Dis 2020, doi:10.1093/cid/ciaa478

[76] Deutsche Diabetes Gesellschaft. Praktische Empfehlungen zum Diabetes-Management bei Patientinnen und Patienten mit einer COVID-19-Erkrankung. In; 2020

[77] Bornstein SR, Rubino F, Khunti K et al. Practical recommendations for the management of diabetes in patients with COVID-19. The Lancet Diabetes \&. Endocrinology 2020; 8: 546-550. DOI: 10.1016/ S2213-8587(20)30152-2 
[78] Ceriello A, Standl E, Catrinoiu D et al. Issues of Cardiovascular Risk Management in People With Diabetes in the COVID-19 Era. Diabetes Care 2020; dc200941. DOI: 10.2337/dc20-0941

[79] Hartmann-Boyce J, Morris E, Goyder C et al. Diabetes and COVID-19: Risks, Management, and Learnings From Other National Disasters. Diabetes Care 2020; dc201192. DOI: 10.2337/dc20-1192

[80] Tadic M, Cuspidi C, Grassi G et al. COVID-19 and arterial hypertension: Hypothesis or evidence? J Clin Hypertens (Greenwich) 2020, doi: $10.1111 /$ jch. 13925

[81] Gao Y, Chen G, Tian H et al. Prevalence of hypertension in china: a cross-sectional study. PloS one 2013; 8: e65938-e65938. DOI: 10.1371 /journal.pone.0065938

[82] Tocci G, Nati G, Cricelli $C$ et al. Prevalence and control of hypertension in the general practice in Italy: updated analysis of a large database. J Hum Hypertens 2017; 31: 258-262. DOI: 10.1038/ jhh.2016.71

[83] Zhang J, Wu J, Sun X et al. Association of hypertension with the severity and fatality of SARS-CoV-2 infection: A meta-analysis. Epidemiol Infect 2020; 148: e106. DOI: 10.1017| s095026882000117x

[84] Huang S, Wang J, Liu F et al. COVID-19 patients with hypertension have more severe disease: a multicenter retrospective observational study. Hypertension Research : Official Journal of the Japanese Society of Hypertension. 2020; 1-8. DOI: 10.1038/s41440-0200485-2

[85] Yanai H. A Significance of High Prevalence of Diabetes and Hypertension in Severe COVID-19 Patients. J Clin Med Res 2020; 12: 389-392. DOI: $10.14740 /$ jocmr 4218

[86] Pranata R, Lim MA, Huang I et al. Hypertension is associated with increased mortality and severity of disease in COVID-19 pneumonia: A systematic review, meta-analysis and meta-regression. Journal of the renin-angiotensin-aldosterone system : JRAAS 2020; 21: 1470320320926899. DOI: 10.1177/1470320320926899

[87] Yang Q, Zhou Y, Wang $X$ et al. Effect of hypertension on outcomes of adult inpatients with COVID-19 in Wuhan, China: A propensity score-matching analysis. Respir Res 2020; 21: 172. DOI: 10.1186/ s12931-020-01435-8

[88] Nandy K, Salunke A, Pathak SK et al. Coronavirus disease (COVID-19): A systematic review and meta-analysis to evaluate the impact of various comorbidities on serious events. Diabetes \& Metabolic Syndrome 2020; 14: 1017-1025. DOI: 10.1016/j.dsx.2020.06.064

[89] Parveen R, Sehar N, Bajpai R et al. Association of diabetes and hypertension with disease severity in covid-19 patients: a systematic literature review and exploratory meta-analysis. Diabetes Research and Clinical Practice 2020; 108295. DOI: 10.1016/j.diabres.2020.108295

[90] Singh AK, Gupta R, Misra A. Comorbidities in COVID-19: Outcomes in hypertensive cohort and controversies with renin angiotensin system blockers. Diabetes \& Metabolic Syndrome 2020; 14: 283-287. DOI: 10.1016/j.dsx.2020.03.016

[91] Kulkarni S, Jenner BL, Wilkinson I. COVID-19 and hypertension. Journal of the renin-angiotensin-aldosterone system : JRAAS 2020; 21: 1470320320927851. DOI: 10.1177/1470320320927851

[92] Gao C, Cai Y, Zhang K et al. Association of hypertension and antihypertensive treatment with COVID-19 mortality: a retrospective observational study. European heart journal 2020; 41: 2058-2066. DOI: 10.1093/eurheartj/ehaa433

[93] Harrison DG, Guzik T], Lob HE et al. Inflammation, immunity, and hypertension. Hypertension (Dallas, Tex : 1979) 2011; 57: 132-140 DOI: 10.1161/HYPERTENSIONAHA.110.163576

[94] De Miguel C, Rudemiller NP, Abais JM et al. Inflammation and hypertension: new understandings and potential therapeutic targets. Current hypertension reports 2015; 17: 507-507. DOI: 10.1007| s11906-014-0507-z
[95] Perrotta M, Lori A, Carnevale L et al. Deoxycorticosterone acetatesalt hypertension activates placental growth factor in the spleen to couple sympathetic drive and immune system activation. Cardiovascular Research 2018; 114: 456-467. DOI: 10.1093/cvr/cvy001

[96] Chou CH, Hung CS, Liao CW et al. IL-6 trans-signalling contributes to aldosterone-induced cardiac fibrosis. Cardiovascular Research 2018; 114: 690-702. DOI: 10.1093/cvr/cvy013

[97] Hanff TC, Harhay MO, Brown TS et al. Is There an Association Between COVID-19 Mortality and the Renin-Angiotensin System-a Call for Epidemiologic Investigations. Clin Infect Dis 2020, doi:10.1093/cid/ciaa329

[98] Zhang P, Zhu L, Cai J et al. Association of Inpatient Use of Angiotensin-Converting Enzyme Inhibitors and Angiotensin II Receptor Blockers With Mortality Among Patients With Hypertension Hospitalized With COVID-19. Circulation Research 2020; 126: 1671-1681. DOI: doi:10.1161/CIRCRESAHA.120.317134

[99] European Society of Hypertension. Statement of the European Society of Hypertension (ESH) on hypertension, Renin-Angiotensin System(RAS) blockers and COVID-19. In; 2020

[100] Kreutz R, Algharably EAE, Azizi M et al. Hypertension, the reninangiotensin system, and the risk of lower respiratory tract infections and lung injury: implications for COVID-19. Cardiovascular Research 2020, doi:10.1093/cvr/cvaa097

[101] Heart Failure Society of America, American College of Cardiology, American Heart Association. HFSA/ACC/AHA Statement Addresses Concerns Re: Using RAAS Antagonists in COVID-19. 2020:

[102] European Society of Cardiology. Position Statement of the ESC Council on Hypertension on ACE-Inhibitors and Angiotensin Receptor Blockers 2020:

[103] Deutsche Gesellschaft für Kardiologie. COVID-19 und Behandlung mit Hemmstoffen des Renin-Angiotensin-Systems. In; 2020

[104] World Hypertension League. COVID-19 hypertension guidance. In; 2020

[105] Guo T, Fan Y, Chen M et al. Cardiovascular Implications of Fatal Outcomes of Patients With Coronavirus Disease 2019 (COVID-19). JAMA cardiology 2020; 5: 1-8. DOI: 10.1001/jamacardio.2020.1017

[106] Aggarwal G, Cheruiyot I, Aggarwal S et al. Association of Cardiovascular Disease With Coronavirus Disease 2019 (COVID-19) Severity: A Meta-Analysis. Curr Probl Cardiol 2020; 45: 100617-100617. DOI: 10.1016/j.cpcardiol.2020.100617

[107] Zhou F, Yu T, Du R et al. Clinical course and risk factors for mortality of adult inpatients with COVID-19 in Wuhan, China: a retrospective cohort study. The Lancet 2020; 395: 1054-1062. DOI: 10.1016/ S0140-6736(20)30566-3

[108] Ruan Q, Yang K, Wang W et al. Clinical predictors of mortality due to COVID-19 based on an analysis of data of 150 patients from Wuhan, China. Intensive Care Medicine 2020; 46: 846-848. DOI: 10.1007| s00134-020-05991-x

[109] Li X, Guan B, Su T et al. Impact of cardiovascular disease and cardiac injury on in-hospital mortality in patients with COVID-19: a systematic review and meta-analysis. Heart (British Cardiac Society) 2020; 106: 1142. DOI: 10.1136/heartjnl-2020-317062

[110] Zhang ], Lu $S$, Wang $X$ et al. Do underlying cardiovascular diseases have any impact on hospitalised patients with COVID-19? Heart (British Cardiac Society) 2020; 106: 1148-1153. DOI: 10.1136/ heartjnl-2020-316909

[111] Xu Z, Shi L, Wang Y et al. Pathological findings of COVID-19 associated with acute respiratory distress syndrome. The Lancet Respiratory Medicine 2020; 8: 420-422. DOI: 10.1016/\$2213. 2600(20)30076-X

[112] Inciardi RM, Lupi L, Zaccone G et al. Cardiac Involvement in a Patient With Coronavirus Disease 2019 (COVID-19). JAMA cardiology 2020; 5: 819-824. DOI: 10.1001/jamacardio.2020.1096 
[113] Shi S, Qin M, Shen B et al. Association of Cardiac Injury With Mortality in Hospitalized Patients With COVID-19 in Wuhan. China. JAMA cardiology 2020, doi:10.1001/jamacardio.2020.0950

[114] Zheng Y-Y, Ma Y-T, Zhang J-Y et al. COVID-19 and the cardiovascular system. Nature Reviews. Cardiology 2020; 17: 259-260. DOI: 10.1038/s41569-020-0360-5

[115] Madjid M, Safavi-Naeini P, Solomon SD et al. Potential Effects of Coronaviruses on the Cardiovascular System: A Review. JAMA cardiology 2020, doi:10.1001/jamacardio.2020.1286

[116] Lindner D, Fitzek A, Bräuninger $\mathrm{H}$ et al. Association of Cardiac Infection With SARS-CoV-2 in Confirmed COVID-19 Autopsy Cases. JAMA cardiology 2020, doi:10.1001/jamacardio.2020.3551

[117] Cooper LT. Myocarditis. New England Journal of Medicine 2009; 360: 1526-1538. DOI: 10.1056/NEJMra0800028

[118] Lala A, Johnson KW, Januzzi JL et al. Prevalence and Impact of Myocardial Injury in Patients Hospitalized With COVID-19 Infection. J Am Coll Cardiol 2020; 76: 533-546. DOI: 10.1016/j.jacc.2020.06.007

[119] Xiong T-Y, Redwood S, Prendergast B et al. Coronaviruses and the cardiovascular system: acute and long-term implications. European Heart Journal 2020; 41: 1798-1800. DOI: 10.1093/eurheartj/ ehaa231

[120] Rowland B, Kunadian V. Challenges in the management of older patients with acute coronary syndromes in the COVID-19 pandemic. Heart (British Cardiac Society) 2020, heartjnl-2020-317011 DOI: doi:10.1136/heartjnl-2020-317011

[121] Wu Q, Zhou L, Sun X et al. Altered Lipid Metabolism in Recovered SARS Patients Twelve Years after Infection. Sci Rep 2017; 7: 9110. DOI: 10.1038/s41598-017-09536-z

[122] European Society of Cardiology. ESC Guidance for the Diagnosis and Management of CV Disease during the COVID-19 Pandemic. In; 2020

[123] Han $\mathrm{Y}$, Zeng $\mathrm{H}$, jiang $\mathrm{H}$ et al. CSC Expert Consensus on Principles of Clinical Management of Patients With Severe Emergent Cardiovascular Diseases During the COVID-19 Epidemic. Circulation 2020; 141: e810-e816. DOI: doi:10.1161/CIRCULATIONAHA.120.047011

[124] American Heart Association. Coronavirus (COVID-19). In; 2020

[125] American College of Cardiology. COVID-19 Clinical Guidance for Global Cardiovascular Clinicians. In; 2020

[126] Zaman S, Maclsaac Al, Jennings GL et al. Cardiovascular disease and COVID-19: Australian and New Zealand consensus statement. The. Medical journal of Australia 2020, doi:10.5694/mja2.50714

[127] Deutsche Gesellschaft für Kardiologie. Notfallversorgung von Patienten mit akuten Herzerkrankungen während der Corona-Pandemie. In; 2020

[128] Fragala MHWK, Meigs J et al. Consequences of the COVID-19 Pandemic: Reduced Hemoglobin A1c Diabetes Monitoring. Population Health Management 2020, doi:10.1089/pop.2020.0134

[129] Karter AJ, Parker MM, Moffet HH et al. Missed appointments and poor glycemic control: an opportunity to identify high-risk diabetic patients. Medical Care 2004; 42: 110-115. DOI: 10.1097/01. mlr.0000109023.64650.73

[130] Samuels TA, Bolen S, Yeh HC et al. Missed opportunities in diabetes management: a longitudinal assessment of factors associated with sub-optimal quality. J Gen Intern Med 2008; 23: 1770-1777. DOI: 10.1007/s11606-008-0757-z

[131] Bonora BM, Boscari F, Avogaro A et al. Glycaemic Control Among People with Type 1 Diabetes During Lockdown for the SARS-CoV-2 Outbreak in Italy. Diabetes Ther 2020; 1-11. DOI: 10.1007| s13300-020-00829-7
[132] Capaldo B, Annuzzi G, Creanza A et al. Blood Glucose Control During Lockdown for COVID-19: CGM Metrics in Italian Adults With Type 1 Diabetes. Diabetes Care 2020, doi:10.2337/dc20-1127

[133] Maddaloni E, Coraggio L, Pieralice $S$ et al. Effects of COVID-19 Lockdown on Glucose Control: Continuous Glucose Monitoring Data From People With Diabetes on Intensive Insulin Therapy. Diabetes Care 2020; 43: e86-e87. DOI: 10.2337/dc20-0954

[134] Baum A, Schwartz MD. Admissions to Veterans Affairs Hospitals for Emergency Conditions During the COVID-19 Pandemic. Jama 2020; 324: 96-99. DOI: $10.1001 /$ jama.2020.9972

[135] Lazzerini M, Barbi E, Apicella A et al. Delayed access or provision of care in Italy resulting from fear of COVID-19. The Lancet Child \& Adolescent Health 2020; 4: e10-e11. DOI: 10.1016/S23524642(20)30108-5

[136] Slagman A, Behringer W, Greiner F et al. Medical Emergencies During the COVID-19 Pandemic. Dtsch Arztebl International 2020; 117: 545-552. DOI: 10.3238/arztebl.2020.0545

[137] Kamrath C, Mönkemöller K, Biester T et al. Ketoacidosis in Children and Adolescents With Newly Diagnosed Type 1 Diabetes During the COVID-19 Pandemic in Germany. Jama 2020, doi:10.1001/ jama.2020.13445

[138] Garcia S, Albaghdadi MS, Meraj PM et al. Reduction in ST-Segment Elevation Cardiac Catheterization Laboratory Activations in the United States During COVID-19 Pandemic. Journal of the American College of Cardiology 2020; 75: 2871-2872. DOI: https://doi. org/10.1016/j.jacc.2020.04.011

[139] Solomon MD, McNulty EJ, Rana JS et al. The Covid-19 Pandemic and the Incidence of Acute Myocardial Infarction. New England Journal of Medicine 2020, doi:10.1056/NEJMc2015630

[140] De Filippo O, D’Ascenzo F, Angelini F et al. Reduced Rate of Hospital Admissions for ACS during Covid-19 Outbreak in Northern Italy. The. New England Journal of Medicine 2020; 383: 88-89. DOI: 10.1056/ NEJMc2009166

[141] Marijon E, Karam N, Jost D et al. Out-of-hospital cardiac arrest during the COVID-19 pandemic in Paris, France: a population-based, observational study. The Lancet Public Health 2020, doi:10.1016/ S2468-2667(20)30117-1

[142] Puntmann VO, Carerj ML, Wieters I et al. Outcomes of Cardiovascular Magnetic Resonance Imaging in Patients Recently Recovered From Coronavirus Disease 2019 (COVID-19). JAMA Cardiology 2020, doi:10.1001/jamacardio.2020.3557

[143] Pierce M, Hope H, Ford T et al. Mental health before and during the COVID-19 pandemic: a longitudinal probability sample survey of the UK population. The Lancet Psychiatry 2020, doi:10.1016/S22150366(20)30308-4

[144] Bhaskar S, Rastogi A, Chattu VK et al. Key Strategies for Clinical Management and Improvement of Healthcare Services for Cardiovascular Disease and Diabetes Patients in the Coronavirus (COVID-19) Settings: Recommendations From the REPROGRAM Consortium. Frontiers in Cardiovascular Medicine 2020; 7: 112. DOI: 10.3389/ fcrm.2020.00112

[145] Chudasama YV, Gillies CL, Zaccardi F et al. Impact of COVID-19 on routine care for chronic diseases: A global survey of views from healthcare professionals. Diabetes \& metabolic syndrome 2020; 14 965-967. DOI: 10.1016/j.dsx.2020.06.042

[146] Emerging Infections Task Force. Lean European Open Survey on SARS-CoV-2 infected patients" (LEOSS) database and research platform In; 2020 